\title{
Łukasz Sobczak
}

\section{ITINERARIUM WIELKIEGO MISTRZA ZAKONU KRZYŻACKIEGO KONRADA ZÖLLNERA VON ROTENSTEIN (1382-1390)}

\section{Uwagi wstępne}

Wielki mistrz zakonu krzyżackiego Konrad Zöllner von Rotenstein nie doczekał się jak do tej pory publikacji, w której opracowano jego itinerarium ${ }^{1}$. O znaczeniu sporządzania wykazów podróży w nauce pisal Antoni Gąsiorowski: „zêstawienie itinerariów uzupełnia możliwości badawcze studiów nad majątkiem królewskim i sposobem jego użytkowania poprzez system stacji oraz had średniowieczną skarbowością (świadczenia na rzecz króla ze strony miast i klasztorów w postaci stacji, podwód, ospów). Studium itinerariów pomaga poznać średniowieczny system komunikacji, przebieg dróg, usytuowanie przepraw itp. Duże znacznie mają też itineraria dla dyplomatyki, pozwalając na kontrolę dat dokumentów królewskich i związanych z królem, ułatwiając w sposób znaczny studia nad kancelariami królewskimi”"2. Największy wkład w badanie mobilności wielkich mistrzów zakonu krzyżackiego ma Klaus Neitmann, twórca itinerariów Konrada von Jungingen, Michała Küchmeistra i Konrada von Erlichshausen ${ }^{3}$. K. Neitmann ponadto wykorzystał itineraria zestawione przez innych badaczy, korygując je i wydając na nowo ${ }^{4}$. Itinerarium poświęcone Winry-

\footnotetext{
${ }^{1}$ Istnieje wiele definicji itinerariów, najtrafniejszą jednak w odczuciu autora podał Stanisław Kościałkowski: „Itinerarium (od słowa łacińskiego «iter» - gen. «itineris» - droga, podróż) jest to sporządzony, nieraz drogą żmudnych dociekań badawczych, wykaz miejscowości, w których pewna postać historyczna (papież, król, znakomity działacz czy wódz, wielki poeta) w ciągu całego życia lub w pewnym okresie tegoż przebywała”, S. Kościałkowski, Historyka - wstęp do studiów historycznych, Londyn 1954, s. 70. Z innymi definicjami itinerarium można zapoznać się w: P. Węcowski, Polskie itineraria średniowieczne i nowożytne. Przegląd badań i propozycje badawcze, Studia Źródłoznawcze, 2000, t. XXXVII, s. 14.

${ }^{2}$ A. Gąsiorowski, Itinerarium króla Władysława Jagiełly (1386-1414), Warszawa 1972, s. 9.

${ }^{3}$ K. Neitmann, Der Hochmeister des Deutschen Ordens In Preussen - ein Residenzherrscher unterwegs. Untersuchungen zu den Hochmeisteritineraren im 14. und. 15. Jahrhundert, Köln-Wien 1990.

${ }^{4}$ Są to: W. Nöbel, Michael Küchmeister Hochmeister des Deutschen Ordens 1414-1422, Bad Godesberg 1969; C. A. Lückerath, Paul von Rusdorf Hochmeister des Deutschen Ordens 1422-1441, Bad Godesberg 1969. Obie pozycje zostały wydane w serii Quellen und Studien zur Geschichte des Deutschen Ordens.
} 
chowi von Kniprode za lata 1352-1361 zestawił Bernhart Jähnig5. O pozostałe lata panowania uzupełnił je Walther Hubatsch, niestety, itinerarium to jest niekompletne i wymaga licznych poprawek ${ }^{6}$. Oba zestawienia połączył w sposób graficzny wspomniany B. Jähnig7. Graficzny sposób przedstawienia pobytów wielkiego mistrza jest jednak nieprecyzyjny, uogólnia bowiem miejsca pobytu do obszarów geograficznych, nie zaś do poszczególnych miejsc. Nie zawiera ono również dokładnych dat dziennych, jedynie podział na miesiące.

Największy zbiór dokumentów, które zostały wykorzystane przy tworzeniu itinerarium Konrada Zöllnera von Rotenstein zebrał i opracował Harro Gersdorf w monografii poświęconej czasom jego panowania ${ }^{8}$. Dokumenty zebrane przez H. Gersdorfa obejmują nie tylko czas piastowania przez Konrada urzędu wielkiego mistrza, ale także okres, gdy pełnił on niższe funkcje w zakonie krzyżackim. Zebrano tam również dokumenty, które wystawiane były za wiedzą wielkiego mistrza. Zestawienie stworzone przez H. Gersdorfa wykonane jest rzetèlnie i nie budzi większych zastrzeżeń. Każdy z aktów posiada rozwiązaną datę, określone miejsce, krótki i rzeczowy regest, spis świädków oraz miejsce, gdzie znajduje się oryginał dokumentu. Niezwykle przydatne jest także, zaznaczone przez autora, miejsce występowania danego dokumentu w innych opracowaniach źródłowych, ponieważ pozwala ono na porównanie obu edycji źródłowych w celu kontroli dat, miejsc nadania i treści. Nie można jednak uznać zestawienia poczynionego przez Gersdorfa itinerarium za idealne, ponieważ nie obejmuje ono wszystkich informacji poświadczających mobilność mistrza Konrada. Niezbędnym jest więc rozszerzenie wspomnianego zestawienia.

Itinerarium przedstawiono $\mathrm{w}$ formie kolumn, w których obok dat i miejsc zawarto informację o źródle, z którego pochodzi przekaz o obecności wielkiego mistrza w danym miejscu. Nazwy miejscowości podano w ich współczesnej wersji oraz w oryginale (pisane kursywą). Do itinerarium dołączono również wykaz używanych skrótów.

${ }^{5}$ B. Jähnig, Hat Keiser Karl IV. im Jahre 1355 mit Hochmeister Winrich von Kniprode verhandlet? Ein Beitrag zu Regierungsstil und Diplomatiegeschichte des Deutschen Ordens im 14. Jahrhundert, Blätter für deutsche Landesgeschichte, Bd. 116, 1980, ss. 77-119.

${ }^{6}$ W. Hubatsch, Winrich von Kniprode, Hochmeister des Deutschen Ordens 1352-1382, Blätter für deutsche Landesgeschichte, Bd. 119, 1983, ss. 15-32.

${ }^{7}$ B. Jähnig, Winrich von Kniprode - Hochmeister des Deutschen Ordens 1352-1382, Jahrbuch Preußischer Kulturbesitz, B. 19, 1982, ss. 249-276.

${ }^{8}$ H. Gersdorf, Der Deutsche Orden im Zeitalter der polnisch-litauischen Union: die Amtszeit des Hochmeisters Konrad Zöllner von Rotenstein (1382-1390), Marburg/Lahn 1957. 
Itinerarium wielkiego mistrza zakonu krzyżackiego Konrada Zöllnera von Rotenstein 659

2. Itinerarium wielkiego mistrza Konrada Zöllnera von Rotenstein (1382-1390)

\section{Rok 1382}

Data

2 X - wybór na Malbork wielkiego mistrza
$31 \mathrm{X}$

Wyspa na rzece Dubissa

\section{Źródło}

Annalista s. 120.

Regesta II nr 1091

Regesta II nr 1092

CEV nr 4

Regesta II nr 1090

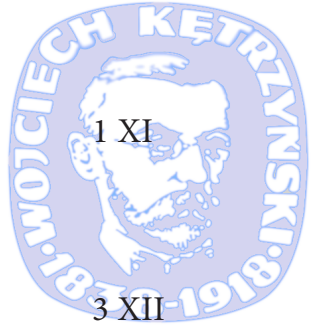

28 XII

\section{IM.}

IN Syspa na rzece Dubissa

Człuchów

(Schlochau)

Malbork

(Marienburg)

\section{Rok 1383}

17 II

Olsztynek

HG nr 52

(Hohenstein)

20 II

Dąbrówno

HG nr 54

(Gilgenburg)

$21 \mathrm{II}$
HG nr 50/

Schlochau nr 141

HG nr 51/

UBK nr 363 
(Lutterburgk)

Luty - kwiecień

9 III

Po 22 III

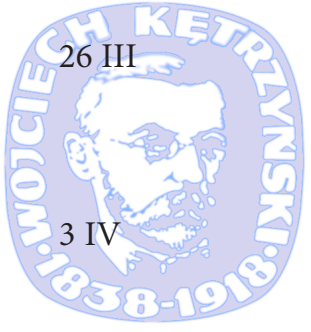

$4 \mathrm{IV}$

$15 \mathrm{IV}$

23 IV

$12 \mathrm{~V}$
Swornegacie

(Schwornigatz)

Malbork

Sambia, Natangia

Elbląg

(Elbing)

Bartoszyce

(Bartenstein)

Neuenburg

Niżowe

(Waldau)

Mielnikow

(Rudau)

Malbork
CEV nr 8

HG nr 57/

Tuchel nr 91

HG nr 58

Annalista s. 124

HG nr 59/60

CDW 151

CDPruss. nr 18/

HUB nr 773/

Pr. UB JS-JP 23

Hanserecesse nr 166

HG nr 61

HG nr 62/

Regesta II nr 1100

HG nr 63/

Regesta I nr 427

HG nr 64 
Itinerarium wielkiego mistrza zakonu krzyżackiego Konrada Zöllnera von Rotenstein 661 $28 \mathrm{~V}$ Świecie

HG nr 65

(Schwetz)

$31 \mathrm{~V}$

Starogard Gdański

HG nr 66

(Stargard)

$13 \mathrm{VI}$

Pasłęk

CDPruss. nr 15/

(Preussisch Holland)

CDW nr 153/

$25 \mathrm{VI}$

Przezmark

Pr. UB JS-FS 13

(Preussisch Mark)

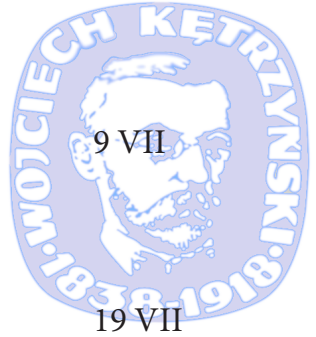

(Preussisch Mark)

IN S Uszakowo (Pokarmin) EN $\mathbb{N} O C \mathbb{N}$ H nr 69 $\mathbb{I M}$.

(Brandenburg)

Christmemel

Annalista s. 125

26 VII

Kaliningrad (Królewiec)

HG nr 70

(Königsberg)

30 VII

Malbork

CEV nr 10/

LUB nr 1239

15 VIII

?

Wigand s. 622

15 VIII

?

Regesta II nr 1102

$?$

Litwa

Długosz s. 176

11 IX

Troki

Annalista s. 124/

Wigand s. 622 
$11 \mathrm{X}$

$21 \mathrm{X}$
Malbork

Gwardiejsk (Tapiawa)
CDW nr 157

HG 71

Wigand, s. 623.

\section{Rok 1384}

$1 \mathrm{I}$

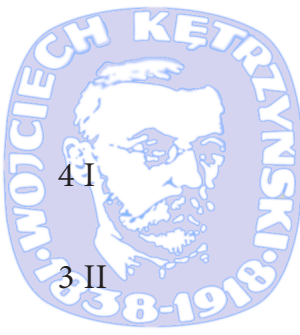

15 II

12 III

28 III

14 IV

$15 \mathrm{IV}$

17 IV
Malbork

C. epist. XV nr 1/

CEV nr 12/

Lewicki nr 22

\section{Malbork HG nr 72}

Malbork

Gdańsk (Danzig)

Przezmark

Lębork

(Lauenburg)

Elbląg

Malbork

Malbork
HG nr 75

HG nr 73/

CDW nr 166

APG 368/I 32

APG 300D/ 46,7

Pr. UB JS-FS 20

Regesta II 1110

Regesta II 1111/Regesta

II 1112

HG nr 76

HG nr 77 
Itinerarium wielkiego mistrza zakonu krzyżackiego Konrada Zöllnera von Rotenstein 663

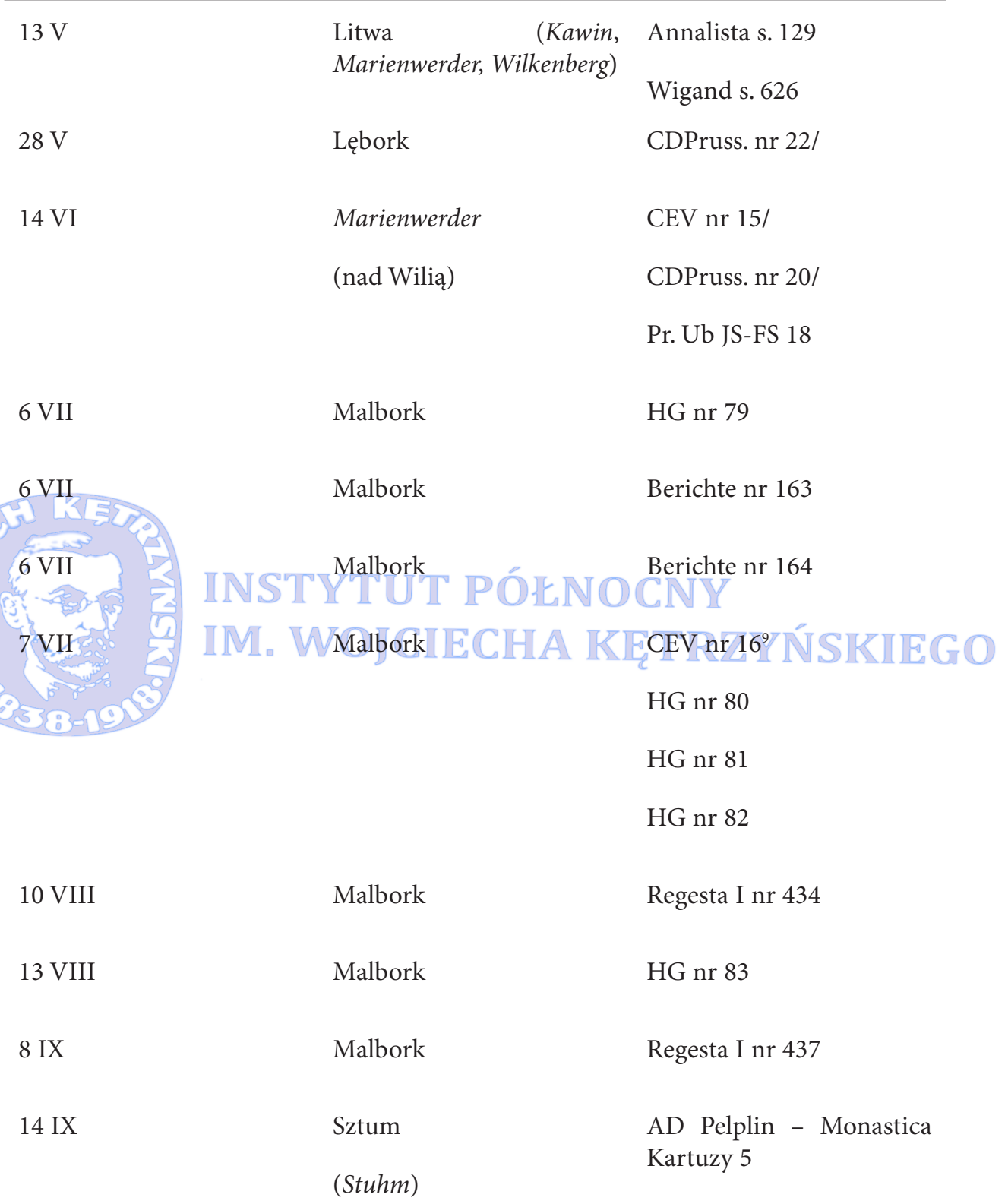

${ }^{9}$ Regest w CEV pozbawiony jest miejsca wydania. 
KKG nr 9

$18 \mathrm{XI}$

Działdowo

HG nr 90

(Soldaw)

$27 \mathrm{XI}$

Toruń

APT nr 41/

(Thorn)

UBK nr 365

$28 \mathrm{XI}$

Bierzgłowo

APT nr 42/

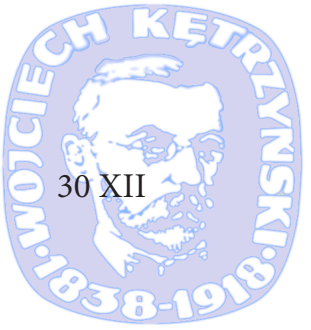

(Birgelau)

CDPruss. nr 27/

Pr. UB JS-FS 25

\section{Rok 1385}

23 I

Malbork

CDW nr 180/

APG 368/I 28

AST 22

24 I

Malbork

APT nr $43 / 44$

HUB nr 810/811

Pr.UB JS-JP $6^{10} /$ JS-JP 7

7 II

Elbląg

HG nr 94/95

${ }^{10}$ Brak miejsca. 
Itinerarium wielkiego mistrza zakonu krzyżackiego Konrada Zöllnera von Rotenstein 665

13 III

Tuchola

HG nr 98/99

(Tuchel)

Schlochau nr 146/147

14 III

Kosobudy

HG nr 100/

(Kossabude)

Tuchel nr 94

8 IV

Elbląg

CDW nr 183

15 IV

Sobowidz

APG 942/22

(Sobowitz)

HG nr 102

\section{IV}

Królewiec

CEV nr 18

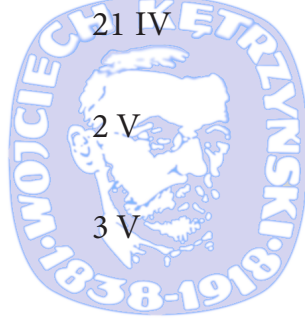

INSGdańsk UT PÓZENOCNAPG 300D/70,20

Sztum

APT nr 45/

HUB nr 830/

Pr. UB JS-JP 10

$?^{11}$

?

APT nr 46

$30 \mathrm{~V}$

Wyspa na rzece Dubissa

CEV nr 20

12 VII

Elbląg

HG nr 103

${ }^{11}$ Brak informacji o miejscu i dacie. Według A. Radzimińskiego i J. Tandeckiego koncept dokumentu mógł powstać, podobnie jak w przypadku dokumentu z $3 \mathrm{~V}, \mathrm{w}$ Toruniu, co wskazywałoby na podobny czas i miejsce powstania obu dokumentów. 


\section{Rok 1386}

1 I

25 II

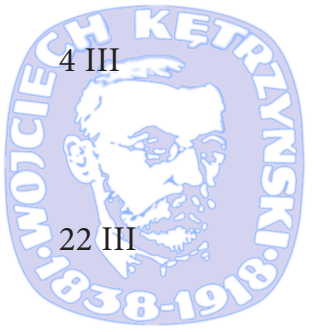

$2 \mathrm{~V}$
Malbork

Gdańsk

Gniew

(Mewe) UI POUNPr. UB JS-JP 39

Swornegacie

Malbork

AST nr 26/28

CDPruss. nr 39/

CDW 196

UBK nr 372/373

Posilge s. 142/

Pr. UB JS-FS 37/

Regesta I nr 446/447; Regesta

II nr 1131

Malbork
Regesta I nr 438; Regesta II nr. 1117 
Itinerarium wielkiego mistrza zakonu krzyżackiego Konrada Zöllnera von Rotenstein 667 $17 \mathrm{~V}$ Gdańsk

APG 300D/79, 141

$3 \mathrm{VI}$

Malbork

Cramer s. 106/

Regesta II nr 1135

$24 \mathrm{VI}$

Nowe

Wegner s. 302

(Neuenburg)

10 VII

Lębork

APG 300D/37,9/

CDPruss. nr 38

Lewicki nr 34

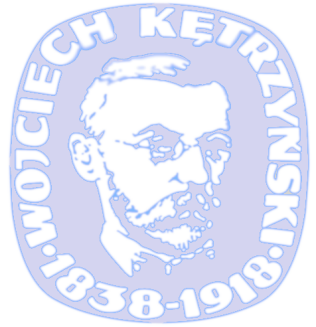

$12 \mathrm{VII}$

16 VII

2 VIII

4 VIII

przed 5 VIII

5 VIII

\section{INST
Lębork}

Starogard Gdański

Malbork

Elbląg

?

?
PrUB JS-FS 3/PrUB JS-FS

34/PrUBJS-FS 36

Regesta I nr 409; Regesta II

nr 1136, nr 1137, nr 1138

AST 30

HG nr 111

HG nr 112

Schwengel ss. 413-415

HG nr 113

PrUB JS-JP 44

APT nr 47/

CDPruss. nr 40

HUB nr 876 
16 VIII

Malbork

30 VIII

$8 \mathrm{X}$

$18 \mathrm{X}$

$26 \mathrm{X}$

$30 \mathrm{XI}$

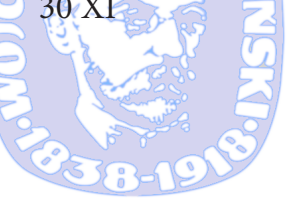

17 I

7 II

$13 \mathrm{IV}$

$1 \mathrm{~V}$

$4 \mathrm{VI}$
Malbork

Malbork

Malbork

Malbork

Malbork

Malbork

Malbork

Malbork

Elbląg

Drużnoje

(Wargen)
PrUB JS-FS 35/

Regesta II nr 1141/

APG 368/II 15

CDW nr 200

HG nr 114

CDW nr 201

HG nr 116

PrUB JS4

HG nr 120

HG nr 132

HG nr 134

Regesta II nr 1146

HG nr 136 
Itinerarium wielkiego mistrza zakonu krzyżackiego Konrada Zöllnera von Rotenstein 669

$\begin{array}{ll}\text { Kwidzyn } & \text { CDW nr 213/ } \\ \text { (Marienwerder) } & \text { Cramer s. 106/ } \\ & \text { Regesta II nr 1147/ } \\ & \text { UBK nr } 377\end{array}$

28 VI Nowe HG nr 137

9 VII $^{12} \quad$ Im campo Curtzem Lewicki nr 55/

LUB nr 1240

$27 \mathrm{VH} \quad$ Malbork $\quad$ Pr. UB DH 338

15 VIII

$8 \mathrm{IX}$ is $I \mathbb{N}$ Malbork] CIIECIIA IKAPG 300D/40,31

24 IX Malbork HG nr 143

Regesta II 1150

27 IX

Sztum

HG nr 144

$1 \mathrm{X}$

Malbork

HG nr 145

$13 \mathrm{X}$

Wierzbica

HG nr 146

(Vierzighuben)

$11 \mathrm{XI}$

Malbork

Regesta I nr 453; II nr 1153

3 XII

Malbork

HG nr 148

26 XII

Malbork

Berichte nr 173

${ }^{12} \mathrm{~W}$ opracowaniu A. Lewickiego dokument ten występuje bez miejsca i dokładnej daty (post Martium). 


\section{Rok 1388}

?

Bagrationowsk

HG nr 149

(Pruska Iława)

(Eylaw)

?

Bagrationowsk

HG nr 150

(Pruska Iława)

$21 \mathrm{I}$

Malbork

Lewicki nr 74

3 II

Sztum

HG nr 154

$16 \mathrm{III}^{13}$

Sztum

YTUT POENONOCAPTnr 50

11-21 IV

Toruń - Raciąż

ECIIA KMIE CEV nr 391

Annalista ss. $150-151$.

22 IV

Toruń

Regesta II 1160

$28 \mathrm{IV}$

Świecie

Regesta I nr 456

$30 \mathrm{IV}$

Świecie

CDPruss 48

Regesta II 1161

$7 \mathrm{~V}$

Einsidel

Berichte nr 176/

CDPruss. nr 52/

CEV nr 41/

PrUB JS-FS 48

${ }^{13}$ Data roczna ustalona przez autorów w oparciu o M. Magdański, Organizacja kupiectwa i handlu toruńskiego do roku 1403, Toruń 1939. 
Itinerarium wielkiego mistrza zakonu krzyżackiego Konrada Zöllnera von Rotenstein 671

$15 \mathrm{~V}$

Drużnoje

HG nr 157/158

Regesta II 1162

$20 \mathrm{~V}$

Gwardiejsk (Tapiawa)

HG nr 159

(Tapiau)

$21 \mathrm{~V}$

Gwardiejsk (Tapiawa)

HG nr 160/161

$25 \mathrm{~V}$

Barciany

HG nr 162/163

(Barten)

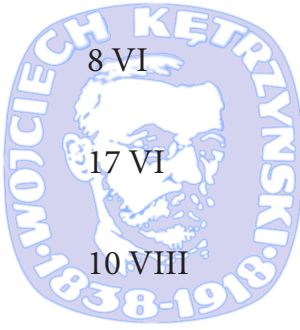

Elbląg

HG nr 164

\section{Malbork}

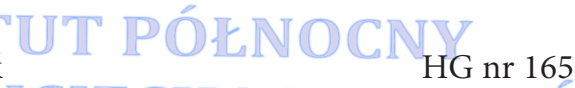

Malbork

CDPruss. nr 50/

CEV nr 45/

PrUB JS-FS 46

21 VIII

Malbork

HUB nr 940/

Pr. UB nr JS-JP 61/

Regesta II nr 1169

po $21 \mathrm{VII}$ ? $^{14}$

?

APT nr 49

Wrzesień

Litwa

Wigand ss. 633-634

$19 \mathrm{X}$

Malbork

Regesta II nr 1170/

Regesta II nr 1171

\footnotetext{
${ }^{14}$ Data dzienna wywnioskowana na podstawie odwołania w treści dokumentu do układu z 21 VIII $1388 \mathrm{r}$.
} 
Lewicki nr $92^{15}$

1 XII

Malbork

HG nr 166

3 XII

Malbork

HG nr 167/

CDW nr 226/

Regesta I nr 465

Regesta II 1172

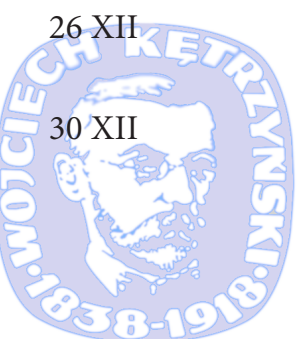

Malbork

Cramer ss. 131-133

początek 1389 roku

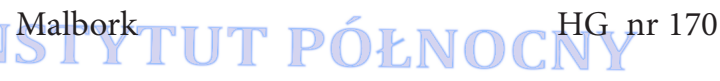
IM

\section{Rok 1389}

6 I

Malbork

HUB nr 958/

HUB nr 959/

PrUB JS-JP 7016/

PrUB JS-JP 72

$10 \mathrm{I}$

Malbork

HG nr 171/172

$21 \mathrm{I}$

Malbork

CDPruss. nr 70/

CEV nr 49

${ }^{15}$ Według tej edycji źródłowej wielki mistrz przebywał in castro Rupino (Rupcow).

${ }^{16}$ Brak miejsca. 
Itinerarium wielkiego mistrza zakonu krzyżackiego Konrada Zöllnera von Rotenstein 673

5 IV Sztum APT nr 53

13 IV Malbork $\quad$ HG nr 175

OFR $1^{17}$

po $16 \mathrm{IV}$

?

OFR 2

$3 \mathrm{~V} \quad$ Człuchów $\quad$ PrUB JS-JL 19

$20 \mathrm{~V}$ Gdańsk APG 300D/ 46,10

23-26 V Gdańsk OFR 4/5/6/7

$\begin{array}{cc}\text { czerwiec }^{18} & \text { Sztum } \\ \text { OFR } 9 / 10\end{array}$

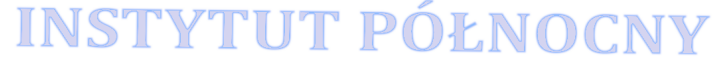

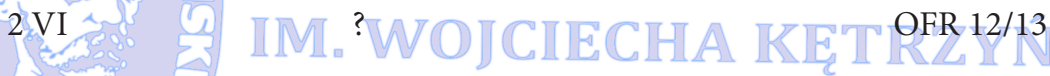

PrUB JS-JP $75^{19}$

$11 \mathrm{VI}$

?

OFR 14

$14 \mathrm{VI}$

Ostróda

CDPruss. nr 60/

(Osterode)

Lewicki nr 104/

OFR 15

Pr. UB JS-FS 6

$16 \mathrm{VI}$

Pasłęk

HG nr 176

${ }^{17}$ Brak miejsca.

${ }^{18}$ Brak daty dziennej.

${ }^{19}$ Oznaczone jako początek czerwca. 
CDPruss. nr 55/

OFR 17

Pr. UB JS-FS 51

Lewicki nr 105

19 VII

Malbork

HUB nr 977/

Pr. UB JS-JP 80

OFR 18

26 VII

Człuchów

CDPruss. nr 58/

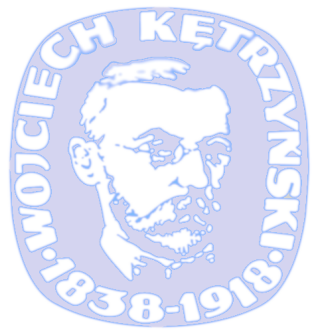

Lewicki nr 107/

27 VII

Czarne

CEV nr 56

(Hammerstein)

OFR 21

31 VII

Człuchów

OFR 23

6 VIII

Świecie

Pr. UB JS-JL 20

OFR 24/25

7 VIII

Grudziądz

OFR 26

8 VIII

Toruń

HUB nr 981/

Lewicki nr 112

OFR 22 
Itinerarium wielkiego mistrza zakonu krzyżackiego Konrada Zöllnera von Rotenstein 675

9 VIII Malbork $\quad$ CDPruss. nr 69

PrUB1389.08.09

Lewicki nr 108

11 VIII

Rogoźno

OFR 27/28

14 VIII

Malbork

HG nr 182

16 VIII

Malbork

HG nr 183

OFR 30/31

$29 \mathrm{VIII}^{-}$

Brodnica

CEV nr 57

(Strasburg)

OFR $32 / 33 / 34$

$31 \mathrm{VHI}$

\section{Brodnica}

CEV nr 58

OFR 35

8 IX

Toruń

CDPruss.nr 63/

OFR 36

Pr. UB JS-JP 81

Lewicki nr 112

9 IX

Nieszawka

Berichte nr 186

(Nessau)

OFR 37

9 IX

Toruń

OFR 38

15 IX

Radzyń Chełmiński

Pr. UB DH 408

(Rehden)

OFR 39/40 
(Engelsburg)

22 IX

$$
\begin{aligned}
& \text { Partęczyny } \\
& \text { (Partenschin) }
\end{aligned}
$$$$
\text { APG } 687 \text { D/47 }
$$

HG nr 184/

OFR 42

Tuchel nr 99

Regesta I nr 480

23 IX

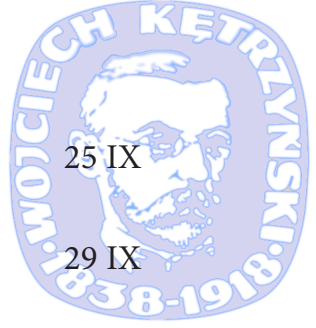

$4 \mathrm{X}$

$5 \mathrm{X}$

$6 \mathrm{X}$

$11 \mathrm{X}$

$22 \mathrm{X}$
Bratian

OFR 43/44

(Brattian)

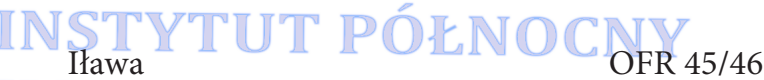

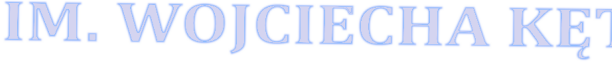
?

Frydrychowicz s. 205

Sztum

Sztum

Sztum

Mątowy Wielkie

(Montau)

Malbork
OFR 48

OFR 49

OFR 50

Cramer s. 106/

Regesta II nr 1189

Lewicki nr 114/

CDPruss. nr 54

OFR 51/52/53/54/55/

$56 / 57$

Pr. UB JS-FS 50 
Itinerarium wielkiego mistrza zakonu krzyżackiego Konrada Zöllnera von Rotenstein 677 $31 \mathrm{X}$

Malbork

CDPruss. nr 72/

CEV nr 61

OFR 58/59

Pr. UB JS-FS 54

$1 \mathrm{XI}$

Malbork

CDPruss. nr 72

13 XI

Malbork

LUB nr 1265

OFR 60

$16 \mathrm{XI}$

Malbork

CEV nr 62

OFR 61

$8 \mathrm{XII}$

22 XII

Malbork

Regesta II nr 1193

24 XII

Malbork

HG nr 187/

Wegner s. 402

Rok 1390

23 III

Malbork

CDPruss. nr 73/

Lewicki nr 129/

PrUB JS-FS 55

$1 \mathrm{~V}$

Sztum

HUB nr 1013/

PrUB JS-FS 3/

PrUB JS-JL 16 
HG nr 190/191

$12 \mathrm{VI}$

Malbork

Regesta II 1204

$13 \mathrm{VI}$

Malbork

HG nr 194

$27 \mathrm{VI}$

Malbork

CEV nr 70

HG nr 195

17 VII

Elbląg

Berichte nr 189/

Lewicki nr 138

$7 \mathrm{VIII}$

Malbork

Berichte nr 190/

INSTYTUT PÓ正 NO C CD̄pruss. nr 78/

IM. WOJ CIE CHA IKE OFR 63/64/65

PrUb JS-FS 60/ JS-FS 61

8 VIII

Malbork

CDPruss. nr 79/

OFR $66^{20} / 67$

PrUb nr JS-FS 59

Lewicki nr 139/140

10 VIII

Malbork

OFR 68

12 VIII

Malbork

OFR 70

13 VIII

Malbork

OFR 71

18 VIII

Malbork

OFR 72

${ }^{20}$ Brak miejsca. 
Itinerarium wielkiego mistrza zakonu krzyżackiego Konrada Zöllnera von Rotenstein 679

20 VIII - dzień

śmierci Konrada Malbork Annalista s. 164.

\section{Wykaz skrótów używanych w itinerarium}

AD Pelplin

Annalista

APG

APT

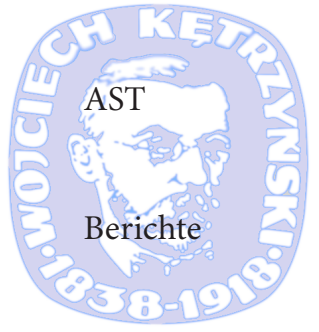

CDPruss.

CDW

C. epist. XV

CEV

Cramer
Archiwum Diecezjalne w Pelplinie.

Annalista Thorunenses, w: Scriptores rerum Prussicarum, bearb. von T. Hirsch, M. Toeppen, E. Strehlke, Bd. 3, Leipzig 1866.

Archiwum Państwowe w Gdańsku.

Katalog dokumentów i listów krzyżackich Archiwum Państwowego w Toruniu. T. 1 (1254-1454), wyd. A. Radzimiński, J. Tandecki, Warszawa, 1994.

Acten des Ständetage Preussens unter der Herrschaft des Deutschen Ordens, hrsg. von M. Toeppen, Bd. I, Leipzig 1874.

Die Berichte der Generalprokuratoren des Deutschen Ordens an der Kurie, bearb. von K. Forstreuter, Bd. 1, Leipzig 1965.

Codex Diplomaticus Prussicus, hrsg.von J.Voigt, Bd. IV, Königsberg 1853.

Codex Diplomaticus Warmiensis oder Regesta und Urkunden zur Geschichte Ermlands, hrsg. von C. P. Woelky, Bd. 3, Leipzig 1874. Codex epistolaris seaculi decimi quinti, ad A. Sokołowski, J. Szujski, w: Monumenta Medii Aevii Historica Res Gestas Poloniae Illustrantia, t. II, Kraków 1876.

Codex Epistolaris Vitoldi magni ducis Lithuaniae 1376-1430, ad A. Prochaska, w: Monumenta Medii Aevii Historica Res Gestas Poloniae Illustrantia, t. VI, p. 1-2, Cracoviae 1882.

Cramer H., Geschichte des vormaligen Bisthums Pomesanien: ein Beitrag zur Landes- und Kirchen -Geschichte des Königreichs Preußen, Marienwerder 1884. 
Długosz

Frydrychowicz

Hanserecesse

HG

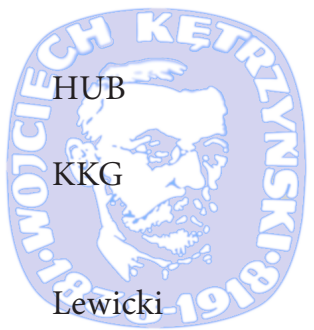

LUB

OFR

Posilge
Jana Dlugosza roczniki czyli kroniki sławnego królestwa polskiego. Księga dziesiąta 1370-1405, tłum. J. Mrukówna, Warszawa 1981 .

Frydrychowicz R., Geschichte der Cistercienserabtei Pelplin und ihre Bau und Kunstdenkmäler, Düsseldorf 1905.

Hanserecesse. Die Recesse und andere Akten der Hansetage, 1. Abt.: von 1256-1430, bearb. von K. Koppmann, Bd. 3, Leipzig 1875.

Gersdorf H., Der Deutsche Orden im Zeitalter der polnisch-litauischen Union: die Amtszeit des Hochmeisters Konrad Zölner von Rotenstein (1382-1390), Marburg 1957.

Hansisches Urkundenbuch, bearb. von K. Künze, Bd.IV, Halle 1896.

Ksiega komturstwa gdańskiego, wyd.

K. Ciesielska, I. Janosz-Biskupowa, Warszawa - Poznań - Toruń 1985.

Index actorum saeculi $X V$ ad res publicas Poloniae spectantium quae quidem typis edita sunt exceptis his. quae dr. A. Prochaska in "Codice Vitoldi” et dr. A. Sokołowski atque dr. J. Szujski in "Codice epistolari saeculi XV" ediderunt, ad A. Lewicki, w: Monumenta Medii Aevii Historica Res Gestas Poloniae Illustrantia, t. XI, Cracoviae 1888. Liv-, Est- und Kurländisches Urkundenbuch nebst Regesten, hrsg. von F. G. von Bunge, H. Hildebrandt, Ph. Schwartz, Bd. III, Reval 1857.

Regesten zu den Briefregistern des Deutschen Ordens: die Ordensfolianten 2a, 2aa und Zusatzmaterial : mit einem Nachdruck von Kurt Lukas: Das Registerwesen der Hochmeister des deutschen Ritterordens, maschinenschrift. phil. Diss. Königsberg 1921, hrsg. und bearb. von S. Kubon, J. Sarnowsky, Göttingen 2012.

Johann von Posilge, w: Scriptores rerum Prussicarum, bearb. von T. Hirsch, M. Toeppen, E. Strehlke, Bd. 3, Leipzig 1866. 
Itinerarium wielkiego mistrza zakonu krzyżackiego Konrada Zöllnera von Rotenstein 681

Pr. Ub

Regesta I/II

Simson

Schlochau

Schwengel

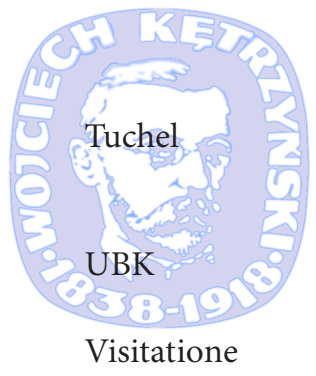

Wegner

Wigand
Das virtuelle Preußische Urkundenbuch: URL: (http://wwwl.uni-hamburg.de/ Landesforschung/orden.html), (19.12.2015) Regesta historico - diplomatica ordinis s. $\mathrm{Ma}$ riae Theutonicorum 1198 - 1525, p. I, II, hrsg. von E. Joachim, W. Hubatsch, Göttingen 1948.

Simson P., Geschichte der Stadt Danzig in 4 Bänden, Bd. 4, Danzig 1913.

Handfeste der komturei Schlochau, bearb. von P. Panske, Danzig 1921.

Georgius Schwengel, Ad historiam ecclesiasticam Pomeraniae apparatus pauper subsidia literaria poscens a viris bonis et doctis collectus ad interim a Georgio Schwengel Cartusiae Priore 1749, wyd. B. Czapla, Toruń 1985.

Urkunden der komturei Tuchel: Handfesten und Zinsbuch, bearb. von P. Panske, Danzig 1911.

Urkundenbuch des Bistums Culm., bearb. von K. P. Woelky, Bd. 1, 1885-1887.

Visitatione im Deutschen Orden im Mittelalter, hrsg. von M. Biskup, I. Janosz-Biskupowa, t. I, Marburg 2002.

Kulturgeschichte des Schwetzer Kreises, bearb. von R. Wegner, Bd. 1, Posen 1872.

Die Chronik Wigands von Marburg, w: Scriptores rerum Prussicarum, bearb. von T. Hirsch, M. Toeppen, E. Strehlke, Bd. 2, Leipzig 1866. 